\title{
Single-nucleotide polymorphism of the $U M O D$ promoter is associated with the outcome of chronic kidney disease patients
}

\author{
LIWEN CUI, YALING BAI, JINSHENG XU, JUNXIA ZHANG, HUIRAN ZHANG, \\ SHENGLEI ZHANG and WENBO ZHANG
}

Department of Nephrology, The Fourth Hospital of Hebei Medical University, Shijiazhuang, Hebei 050011, P.R. China

Received April 5, 2015; Accepted May 21, 2015

DOI: $10.3892 /$ br.2015.471

\begin{abstract}
Uromodulin (UMOD) is the most abundant protein secreted in urine and the mutated form of the $U M O D$ gene is associated with UMOD-associated kidney disease (UAKD). Although UMOD accumulates in the kidney of UAKD patients, it is unclear whether this also occurred in the chronic kidney disease (CKD) patients. Therefore, the association of single-nucleotide polymorphisms (SNPs) in the promoter region of $U M O D$ gene with the kidney survival time of CKD was investigated. The promoter region of the UMOD gene was sequenced for 111 CKD patients. The Kaplan-Meier method was used to identify the disease outcome associated with SNPs in the promoter region of the UMOD gene in CKD patients. The Cox proportional hazard model was used to identify risk factors for the kidney survival time of CKD. SNPs in reference to GenBank accession NG-000016 were detected at 23 sites of the 481-bp in the UMOD promoter region from the CKD patients and the healthy controls. The 6 SNPs with minor allele frequency $>5 \%$ in the CKD patients or controls were used for disease risk and outcome analysis. The frequent allele rs13333226AA was associated with a shorter period of kidney survival time in CKD patients $(\mathrm{P}=0.005)$. The length of kidney survival time in CKD patients with the rs13333226AA genotype was significantly shorter than that of patients with the frequent allele rs13333226AG+GG (relative risk, 0.361; $95 \%$ confidence interval, $0.171-0.761 ; \mathrm{P}=0.007)$. In conclusion, analysis of genetic polymorphisms in $U M O D$ may help to identify the CKD patient subgroups at a high risk for a disease outcome, thereby helping to refine therapeutic decisions in CKD patients.
\end{abstract}

Correspondence to: Dr Jinsheng Xu, Department of Nephrology, The Fourth Hospital of Hebei Medical University, 12 Jiankang Road, Shijiazhuang, Hebei 050011, P.R. China

E-mail: xjs5766@126.com

Key words: outcome, chronic kidney disease, single-nucleotide polymorphism, uromodulin

\section{Introduction}

Chronic kidney disease (CKD) constitutes a serious public health burden worldwide (1). In line with the global trend, the CKD prevalence is also increasing in developing countries $(2,3)$. Recently, based on a report published in the Lancet in 2012, CKD prevalence increases with age and affects $>10 \%$ of the Chinese adult population (4); the estimated prevalence of CKD in China is similar to that reported for developed countries, such as the USA (13\%) (5) and Norway (10\%) (6). CKD can progress to end-stage renal disease (ESRD) that requires dialysis or transplantation. In addition, CKD causes substantial morbidity and is an independent risk factor for cardiovascular disease (7) and over mortality (8).

The major known risk factors for CKD are hypertension and diabetes (9). However, only a few of the individuals exposed to these risk factors will develop CKD in their life time, suggesting that individual differences, including genetic susceptibility factors, may be one of the most critical agents in the incidence of CKD. Identification of genetic risk variants for CKD may provide novel insights into underlying biological mechanisms.

Uromodulin (UMOD) is the most abundant protein in human urine and has been known for $>50$ years (10). Since the discovery of UMOD, increasing research has been performed illustrating its novel roles. Previous studies have indicated that $U M O D$ mutations contribute to familial juvenile hyperuricemia nephropathy, medullary cystic kidney disease 2 (11) and that promoter variants of the UMOD gene are associated with the estimated glomerular filtration rate (eGFR), blood pressure, plasma uric acid level and incidence of CKD (12-14). In the present study, the single-nucleotide polymorphisms (SNPs) were genotyped in the promoter region of the UMOD gene in CKD patients to assess its association with the kidney outcome of CKD.

\section{Materials and methods}

Tissue specimens and DNA extraction. The present study was a prospective trial. Blood samples were obtained from 111 CKD patients at The Fourth Hospital of Hebei Medical University (Hebei, China) between 2002 and 2008. The presence of CKD was defined in accordance with the 2002 National Kidney Foundation Kidney Disease Outcomes 
Quality Initiative classification (15) on the basis of an eGFR of $<60 \mathrm{ml} / \mathrm{min} / 1.73 \mathrm{~m}^{2}$ for $\geq 90$ days. A previous study in China reported an eGFR using the four-variable modified diet in the renal disease formula (16). The etiologies of CKD in these patients were all chronic glomerulonephritis, including membranous nephropathy $(n=64,57.7 \%)$ and non-membranous nephrology $(n=47,42.3 \%)$. The survival period of the kidney was equivalent to the time from CKD diagnosis to ESRD, which was defined as starting dialysis treatment or receiving a renal transplant (17). Total DNA was extracted using a Wizard Genomic DNA extraction kit (Promega Corporation, Madison, WI, USA) and stored at $-20^{\circ} \mathrm{C}$. The study was approved by the Human Tissue Research Committee of The Fourth Hospital of Hebei Medical University. All the patients provided written informed consent for the collection of the samples and subsequent analysis.

Polymerase chain reaction (PCR) amplification and sequence analysis. The forward 5'-TTTCTCCATCCTGTCCCACT-3' (nucleotide 3501-3482) and reverse 5'-ATTCCAACCCAA ACTCCC-3' (nucleotides 3021-3038) primers were used for amplification of a 481-bp product from the UMOD promoter region. PCR was performed according to the manufacturer's instructions of the PCR Master mix kit (Promega Corporation) and purified prior to sequencing. The PCR condition consisted of one incubation of $2 \mathrm{~min}$ at $95^{\circ} \mathrm{C}$, followed by 35 cycles of a 30 -sec denaturation at $95^{\circ} \mathrm{C}$, a $30-\sec$ annealing at $55^{\circ} \mathrm{C}$ and a 45 -sec extension at $72^{\circ} \mathrm{C}$, and a final extension at $72^{\circ} \mathrm{C}$ for 5 min. Cycle sequencing was performed with the Dye Terminator Cycle Sequencing Ready Reaction kit (Applied Biosystem, Foster City, CA, USA) and the products were separated on the ABI PRISM ${ }^{\circledR} 3100$ Genetic Analyzer (Applied Biosystem). Polymorphisms were confirmed by repeated analyses from the two strands.

Statistical analysis. The kidney survival curve was calculated using the Kaplan-Meier method and compared with the log-rank test. Multivariate survival analysis was performed using a Cox proportional hazards model. All the statistical analyses were performed using the SPSS 17.0 software (SPSS, Inc., Chicago, IL, USA). For all the statistical tests, $\mathrm{P}<0.05$ was considered to indicate a statistically significant difference.

\section{Results}

Patient characteristics. A total of 111 CKD patients were enrolled in the present study. At baseline, the mean age of the 111 CKD patients was $57.1 \pm 16.0$ years and $54.1 \%(n=60)$ were males. The mean eGFR was $82.3 \pm 11.6 \mathrm{ml} / \mathrm{min} / 1.73 \mathrm{~m}^{2}$, with $65.8 \%(\mathrm{n}=73)$ of patients having an eGFR $<60 \mathrm{ml} / \mathrm{min} / 1.73 \mathrm{~m}^{2}$. All the participants had an eGFR $>30 \mathrm{ml} / \mathrm{min} / 1.73 \mathrm{~m}^{2}$ (Table I). A review was conducted every 6 months over a 5 -year period. None of these patients were lost to follow-up in the 5 years. Data for the 5-year follow-up period were analyzed with clinical characteristics using the Kaplan-Meier method and were compared by the log-rank test. Age and body mass index were not statistically significant predictors of the length of kidney survival time in CKD patients, but gender, drinking, smoking, proteinuria and eGFR were correlated with kidney survival time in these patients (Table II). The kidney survival rates of
Table I. Baseline characteristics of the CKD participants.

\begin{tabular}{lc}
\hline Variables & All participants \\
\hline Participants, no. & 111 \\
Male, \% & 54.1 \\
Female, \% & 45.9 \\
Median age, years & $57.1 \pm 16.0$ \\
Drinking, \% & \\
Yes & 28.8 \\
No & 71.2 \\
Current smoking, \% & \\
Yes & 43.2 \\
No & 56.8 \\
BMI, kg/m ${ }^{2}$ & $22.2 \pm 2.5$ \\
Hypertension, \% & 87.4 \\
Systolic BP, mmHg & $159.6 \pm 23.9$ \\
Diastolic BP, mmHg & $87.4 \pm 15.7$ \\
MAP, mmHg & $111.4 \pm 16.4$ \\
Etiologies of CKD, \% & \\
Membranous nephrology & 57.7 \\
Non-membranous nephrology & 42.3 \\
eGFR, ml/min/1.73 m ${ }^{2}$ & $82.3 \pm 11.6$ \\
$<60, \%$ & 65.8 \\
\hline
\end{tabular}

BMI, body mass index; MAP, mean arterial pressure; BP, blood pressure; CKD, chronic kidney disease; eGFR, estimated glomerular filtration rate.

female CKD patients were higher than those of male CKD patients; smoking habit showed an association with survival rates of the kidney in CKD patients when survival time of the kidney in smoking CKD patients was lower than those in non-smoking CKD patients. Consistent with the smoking result, the kidney survival time in drinking CKD patients was also lower than that in non-drinking CKD patients. The kidney survival rates of CKD patients with high proteinuria were also lower than those of the CKD patients with low proteinuria. The survival rates of the kidney in CKD patients with eGFR $<60 \mathrm{ml} / \mathrm{min} / 1.73 \mathrm{~m}^{2}$ were lower than those of the kidneys in CKD patients with eGFR $\geq 60 \mathrm{ml} / \mathrm{min} / 1.73 \mathrm{~m}^{2}$. These data demonstrated that gender, drinking, smoking, proteinuria and eGFR of baseline were the risk factors for the kidney survival time of the kidney in the CKD patients.

UMOD promoter SNPs. SNPs in reference to GenBank accession NG-000016 were detected at 23 sites of the 481-bp in the $U M O D$ promoter region from the CKD patients and the healthy controls. SNPs with a minor allele frequency of $<5 \%$ were excluded; thus, a remaining 6 SNPs (rs13332873, rs13332898, rs13332923, rs13333144, rs13333226 and rs13333292) were used for further analysis. At first, the distribution of germline SNPs at each site were compared between CKD patients and healthy controls to identify any link between an SNP and CKD risk; no association with CKD disease risk was detected 
Table II. Univariate analysis of the clinical characteristics associated with the kidney survival time in chronic kidney disease patients.

\begin{tabular}{|c|c|c|c|c|}
\hline Characteristics & $\begin{array}{c}\text { Cases, } \\
\text { no. }\end{array}$ & $\begin{array}{c}5 \text {-year } \\
\text { survival rate } \\
\text { of kidney, } \%\end{array}$ & $\chi^{2}$ test & P-value \\
\hline \multicolumn{5}{|l|}{ Age, years } \\
\hline$\leq 55$ & 49 & 24.5 & 0.234 & 0.629 \\
\hline$>55$ & 62 & 30.6 & & \\
\hline \multicolumn{5}{|l|}{ Gender } \\
\hline Male & 60 & 20.0 & 7.000 & 0.008 \\
\hline Female & 51 & 37.3 & & \\
\hline \multicolumn{5}{|l|}{ Drinking } \\
\hline Yes & 32 & 15.6 & 8.695 & 0.003 \\
\hline No & 79 & 32.9 & & \\
\hline \multicolumn{5}{|l|}{ Smoking } \\
\hline Yes & 48 & 18.8 & 4.327 & 0.038 \\
\hline No & 63 & 34.9 & & \\
\hline \multicolumn{5}{|l|}{$\mathrm{BMI}, \mathrm{kg} / \mathrm{m}^{2}$} \\
\hline$<20$ & 38 & 34.2 & 0.646 & 0.421 \\
\hline$\geq 20$ & 73 & 24.7 & & \\
\hline \multicolumn{5}{|l|}{ MAP, mmHg } \\
\hline$\leq 105$ & 36 & 31.9 & 0.015 & 0.899 \\
\hline$>105$ & 75 & 23.4 & & \\
\hline \multicolumn{5}{|l|}{ Etiologies of CKD } \\
\hline $\begin{array}{l}\text { Membranous } \\
\text { nephrology }\end{array}$ & 57 & 26.4 & 1.245 & 0.262 \\
\hline $\begin{array}{l}\text { Non-membranous } \\
\text { nephrology }\end{array}$ & 54 & 28.3 & & \\
\hline \multicolumn{5}{|l|}{ Proteinuria } \\
\hline High, $\geq 1 \mathrm{~g} / 24 \mathrm{~h}$ & 71 & 16.9 & 11.138 & 0.001 \\
\hline Low, $<1 \mathrm{~g} / 24 \mathrm{~h}$ & 40 & 47.5 & & \\
\hline \multicolumn{5}{|c|}{$\mathrm{eGFR}, \mathrm{ml} / \mathrm{min} / 1.73 \mathrm{~m}^{2}$} \\
\hline$<60$ & 73 & 14.5 & 29.420 & $<0.001$ \\
\hline$\geq 60$ & 38 & 78.3 & & \\
\hline \multicolumn{5}{|l|}{$U M O D(\operatorname{rs} 13333226)$} \\
\hline $\mathrm{AA}$ & 59 & 20.3 & 15.331 & $<0.001$ \\
\hline $\mathrm{AG}+\mathrm{GG}$ & 52 & 36.5 & & \\
\hline
\end{tabular}

BMI, body mass index; MAP, mean arterial pressure; CKD, chronic kidney disease; $U M O D$, uromodulin.

in any SNP in the $U M O D$ gene, with no $\mathrm{P}<0.05$ levels (data not shown).

Association of UMOD genotype and kidney survival time. The association between the UMOD genotype and survival was compared subsequently. The kidney survival curve was plotted using the Kaplan-Meier method and compared with the log-rank test for all the CKD patients at these sites (rs13332873, rs13332898, rs13332923, rs13333144, rs13333226 and rs13333292). The result indicated that none of them are associated with the kidney survival time, except rs13333226
Table III. Multivariate analysis of prognostic factors associated with the kidney survival time in chronic kidney disease patients by the Cox proportional hazards model.

\begin{tabular}{lccr}
\hline Factors & Relative risk & $95 \%$ CI & P-value \\
\hline Gender & 0.703 & $0.353-1.397$ & 0.314 \\
Drinking & 0.823 & $0.434-1.561$ & 0.551 \\
Smoking & 0.848 & $0.431-1.665$ & 0.631 \\
proteinuria & 0.452 & $0.265-0.772$ & 0.004 \\
eGFR & 0.089 & $0.035-0.234$ & $<0.001$ \\
rs13333226 UMOD & 0.361 & $0.171-0.761$ & 0.007 \\
(AA/AG+GG) & & & \\
\hline
\end{tabular}

CI, confidence interval; eGFR, estimated glomerular filtration rate; $U M O D$, uromodulin

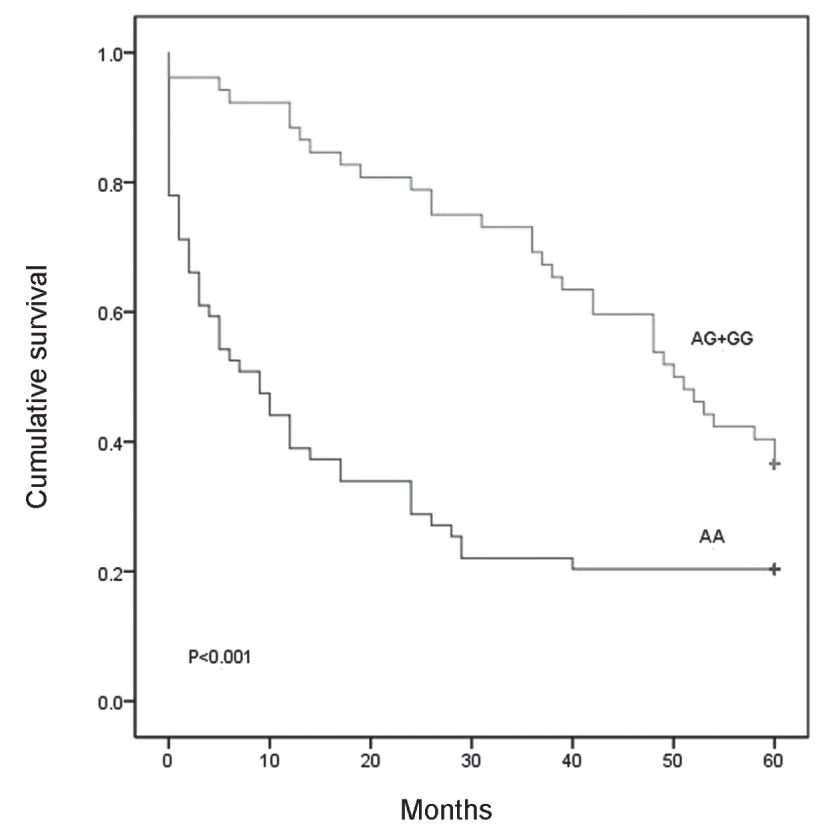

Figure 1. Genotype of $U M O D$ rs13333226 SNPs and their association with the kidney survival of chronic kidney disease patients. $U M O D$, uromodulin; SNP, single-nucleotide polymorphism.

(http://www.ncbi.nlm.nih.gov/snp/). As shown in Fig. 1, the kidney survival time of CKD patients with rs13333226AA was shorter than that of the CKD patients with rs13333226AG+GG $(\mathrm{P}<0.001)$. Multivariate analysis was performed with Cox proportional hazards model, including the factors of gender, smoking, drinking, proteinuria, eGFR and rs13333226. As shown in Table III, the rs13333226 SNP was identified as independent predictors for the kidney survival time in CKD patients. The length of kidney survival time in CKD patients with the rs13333226AA genotype was significantly shorter than that of patients with the frequent allele rs13333226AG+GG [relative risk, 0.361; 95\% confidence interval (CI), 0.171-0.761; $\mathrm{P}=0.007]$. The high proteinuria and low eGFR of the baseline were also the risk factors for the kidney survival time of progressive kidney disease. Gender, smoking and drinking 
were excluded in the multivariate analysis by the Cox proportional hazards model. These data demonstrated the strong prediction power of rs13333226 SNP on the kidney survival time of progressive kidney disease.

\section{Discussion}

UMOD is an 80-90 kDa glycoprotein expressed on the luminal surface of the apical membrane of renal tubular epithelial cells forming the thick ascending limb of Henle $(18,19)$. UMOD may be a factor involved in the pathogenic process of kidney disease. Evidence from studies with humans and mice suggest that the role of UMOD is multifaceted (20-23). One study identified that the elevated urinary UMOD level was a risk factor for the future incidence of CKD (13). However, in diabetes type I it was shown that decreased UMOD excretion was a protective factor for renal failure and cardiovascular disease in adults (21). A study with $U M O D$ knockout mice indicated that UMOD stabilized the outer medulla of the kidney in face of injury by decreasing inflammation (20). In the present study, $111 \mathrm{CKD}$ patients were enrolled to determine the kidney survival-associated germline SNPs in the UMOD gene. The SNP rs13333226AA/AG+GG was identified for the association with kidney survival time in CKD patients at statistically significant levels by the log-rank test. Multivariate survival analysis identified the rs13333226 SNP to be an independent prediction marker for kidney survival time in CKD patients.

Therefore, we suggest that the SNP of UMOD rs13333226 may be a prognostic factor for kidney survival time in CKD patients. The survival time of kidneys in CKD patients with rs13333226AA genotype was significantly shorter than that of the kidney in CKD patients with rs13333226AG+GG (relative risk, 0.361; 95\% CI, 0.171-0.761, P=0.007). Gender, drinking and smoking were excluded in the multivariate analysis by the Cox proportional hazards model. The SNP (rs13333226) that was genotyped in the present study is a common SNP that is associated with serum creatinine, blood pressure or plasma uric acid $(12,24)$. The population genetic studies suggested that the SNP (rs13333226) may influence the transcriptional level and thus regulate $U M O D$ expression and finally change UMOD excretion. However, further cell research should be conducted to confirm the role of the SNP at the rs13333226 site of the $U M O D$ promoter region.

Consistent with earlier reports, the present data demonstrated that gender, smoking, drinking, proteinuria and eGFR were associated with the kidney survival time of CKD patients (25-28), which confirmed the validity of the data. The mechanism explained the association among smoking, drinking and CKD progression is that smoking and drinking all contribute to oxidative stress, which plays an important role in the development and progression of CKD (29). The association between gender and CKD progression suggests that sex hormones may be important determinants of the greater susceptibility of males to progressive kidney injury.

In conclusion, the association of common variants of UMOD with the kidney survival time in CKD patients was identified, suggesting that UMOD has important roles in the progression of CKD. The analysis of genetic polymorphisms in UMOD may help to identify CKD patient subgroups at high risk for a disease outcome, thereby helping to refine therapeutic decisions in CKD patients.

\section{Acknowledgements}

The present study was supported by the project of the Hebei Natural Science Fund (grant no. H2012206157).

\section{References}

1. Zhang QL and Rothenbacher D: Prevalence of chronic kidney disease in population-based studies: Systematic review. BMC Public Health 8: 117, 2008.

2. Nugent RA, Fathima SF, Feigl AB and Chyung D: The burden of chronic kidney disease on developing nations: A 21st century challenge in global health. Nephron Clin Pract 118: c269-c277, 2011.

3. Eknoyan G, Lameire N, Barsoum R, et al: The burden of kidney disease: Improving global outcomes. Kidney Int 66: 1310-1314, 2004.

4. Zhang L, Wang F, Wang L, Wang W, Liu B, Liu J, Chen M, He Q, Liao Y, Yu X, et al: Prevalence of chronic kidney disease in China: A cross-sectional survey. Lancet 379: 815-822, 2012.

5. Coresh J, Selvin E, Stevens LA, Manzi J, Kusek JW, Eggers P, Van Lente F and Levey AS: Prevalence of chronic kidney disease in the United States. JAMA 298: 2038-2047, 2007.

6. Hallan SI, Coresh J, Astor BC, Asberg A, Powe NR, Romundstad S, Hallan HA, Lydersen S and Holmen J: International comparison of the relationship of chronic kidney disease prevalence and ESRD risk. J Am Soc Nephrol 17: 2275-2284, 2006.

7. Sarnak MJ, Levey AS, Schoolwerth AC, Coresh J, Culleton B, Hamm LL, McCullough PA, Kasiske BL, Kelepouris E, Klag MJ, et al; American Heart Association Councils on Kidney in Cardiovascular Disease, High Blood Pressure Research, Clinical Cardiology, and Epidemiology and Prevention: Kidney disease as a risk factor for development of cardiovascular disease: A statement from the American Heart Association Councils on Kidney in Cardiovascular Disease, High Blood Pressure Research, Clinical Cardiology, and Epidemiology and Prevention. Hypertension 42: 1050-1065, 2003.

8. Weiner DE, Tighiouart H, Amin MG, Stark PC, MacLeod B, Griffith JL, Salem DN, Levey AS and Sarnak MJ: Chronic kidney disease as a risk factor for cardiovascular disease and all-cause mortality: A pooled analysis of community-based studies. J Am Soc Nephrol 15: 1307-1315, 2004.

9. Satko SG, Sedor JR, Iyengar SK and Freedman BI: Familial clustering of chronic kidney disease. Semin Dial 20: 229-236, 2007.

10. Tamm I and Horsfall FL Jr: Characterization and separation of an inhibitor of viral hemagglutination present in urine. Proc Soc Exp Biol Med 74: 106-108, 1950.

11. Hart TC, Gorry MC, Hart PS, et al: Mutations of the UMOD gene are responsible for medullary cystic kidney disease 2 and familial juvenile hyperuricaemic nephropathy. J Med Genet 39: 882-892, 2002.

12. Padmanabhan S, Melander O, Johnson T, Di Blasio AM, Lee WK, Gentilini D, Hastie CE, Menni C, Monti MC, Delles C, et al; Global BPgen Consortium: Genome-wide association study of blood pressure extremes identifies variant near UMOD associated with hypertension. PLoS Genet 6: e1001177, 2010.

13. Köttgen A, Pattaro C, Böger CA, Fuchsberger C, Olden M, Glazer NL, Parsa A, Gao X, Yang Q, Smith AV, et al: New loci associated with kidney function and chronic kidney disease. Nat Genet 42: 376-384, 2010.

14. Köttgen A, Glazer NL, Dehghan A, Hwang SJ, Katz R, Li M, Yang Q, Gudnason V, Launer LJ, Harris TB, et al: Multiple loci associated with indices of renal function and chronic kidney disease. Nat Genet 41: 712-717, 2009.

15. Levey AS, Coresh J, Balk E, Kausz AT, Levin A, Steffes MW, Hogg RJ, Perrone RD, Lau J and Eknoyan G; National Kidney Foundation: National Kidney Foundation practice guidelines for chronic kidney disease: Evaluation, classification and stratification. Ann Intern Med 139: 137-147, 2003.

16. Levey AS, Bosch JP, Lewis JB, Greene T, Rogers N and Roth D; Modification of Diet in Renal Disease Study Group: A more accurate method to estimate glomerular filtration rate from serum creatinine: A new prediction equation. Ann Intern Med 130: 461-470, 1999. 
17. Schrier RW, McFann KK and Johnson AM: Epidemiological study of kidney survival in autosomal dominant polycystic kidney disease. Kidney Int 63: 678-685, 2003.

18. Rindler MJ, Naik SS, Li N, Hoops TC and Peraldi MN: Uromodulin (Tamm-Horsfall glycoprotein/uromucoid) is a phosphatidylinositol-linked membrane protein. J Biol Chem 265: 20784-20789, 1990.

19. Kreft B, Jabs WJ, Laskay T, et al: Polarized expression of Tamm-Horsfall protein by renal tubular epithelial cells activates human granulocytes. Infect Immun 70: 2650-2656, 2002

20. El-Achkar TM, Wu XR, Rauchman M, McCracken R, Kiefer S and Dagher PC: Tamm-Horsfall protein protects the kidney from ischemic injury by decreasing inflammation and altering TLR4 expression. Am J Physiol Renal Physiol 295: F534-F544, 2008.

21. Sejdiu I and Torffvit O: Decreased urinary concentration of Tamm-Horsfall protein is associated with development of renal failure and cardiovascular death within 20 years in type 1 but not in type 2 diabetic patients. Scand J Urol Nephrol 42: 168-174, 2008.

22. Zaucke F, Boehnlein JM, Steffens S, Polishchuk RS, Rampoldi L, Fischer A, Pasch A, Boehm CW, Baasner A, Attanasio M, et al: Uromodulin is expressed in renal primary cilia and UMOD mutations result in decreased ciliary uromodulin expression. Hum Mol Genet 19: 1985-1997, 2010.
23. Prajczer S, Heidenreich U, Pfaller W, Kotanko P, Lhotta K and Jennings P: Evidence for a role of uromodulin in chronic kidney disease progression. Nephrol Dial Transplant 25: 1896-1903, 2010.

24. Gudbjartsson DF, Holm H, Indridason OS, Thorleifsson G, Edvardsson V, Sulem P, de Vegt F, d'Ancona FC, den Heijer M, Wetzels JF, et al: Association of variants at UMOD with chronic kidney disease and kidney stones-role of age and comorbid diseases. PLoS Genet 6: e1001039, 2010.

25. Nagasawa Y, Yamamoto R, Rakugi H and Isaka Y: Cigarette smoking and chronic kidney diseases. Hypertens Res 35: 261-265, 2012.

26. Daumit GL, Hermann JA and Powe NR: Relation of gender and health insurance to cardiovascular procedure use in persons with progression of chronic renal disease. Med Care 38: 354-365, 2000.

27. Hsu CY, Iribarren C, McCulloch CE, Darbinian J and Go AS Risk factors for end-stage renal disease: 25 -year follow-up. Arch Intern Med 169: 342-350, 2009.

28. Neugarten $\mathbf{J}$ and Golestaneh L: Gender and the prevalence and progression of renal disease. Adv Chronic Kidney Dis 20: 390-395, 2013

29. Zalba G, Fortuño A and Díez J: Oxidative stress and atherosclerosis in early chronic kidney disease. Nephrol Dial Transplant 21: 2686-2690, 2006. 